\title{
Neocortical layer 6, a review
}

\author{
Alex M. Thomson* \\ Department of Pharmacology, The School of Pharmacy, University of London, London, UK
}

Edited by:

Javier DeFelipe, Cajal Institute, Spain

Reviewed by:

Javier Cudeiro, University de A Coruña,

Spain

Edward G. Jones,

University of California, USA

*Correspondence:

Alex M. Thomson,

Department of Pharmacology, The

School of Pharmacy University of

London, 29-39 Brunswick Square,

London WC1N 1AX, UK.

e-mail:alex.thomson@pharmacy.ac.uk
This review attempts to summarise some of the major areas of neocortical research as it pertains to neocortical layer 6 . After a brief summary of the development of this intriguing layer, the major pyramidal cell classes to be found in layer 6 are described and compared. The connections made and received by these different classes of neurones are then discussed and the possible functions of these connections, with particular reference to the shaping of responses in visual cortex and thalamus. Inhibition in layer 6 is discussed where appropriate, but not in great detail. Many types of interneurones are to be found in each cortical layer and layer 6 is no exception, but the functions of each type remain to be elucidated (Gonchar et al., 2007).

Keywords: cortex, layer 6, anatomy, histology, electrophysiology, pharmacology, development, review

\section{INTRODUCTION}

This review of neocortical layer 6 focuses on primary sensory regions, largely because layer 6 has been more thoroughly studied in these regions than in motor, or association areas. This is not to say that layer 6 has been comprehensively investigated in any region, or that it is possible to define all aspects of its structure and function, in any region. In fact, for many reasons, layer 6 has been studied in rather less detail than layers 3,4 and 5 and it has been necessary here to correlate information from a range of different types of study, different cortical regions and different species, in an attempt to place the knowledge we have in something approaching a functional context. These correlations have been hampered by the fundamental limitations of each technique. For example, in many in vivo extracellular recording studies, the type of neurones recorded could not be identified. This limits the conclusions that can be drawn about the response properties of the several sub-types of layer 6 neurones and any structure-function relationships that might pertain. A number of elegant anatomical studies form the essential platform upon which much of the discussion here resides, but all too few functional studies have even attempted to place their findings in this context.

Layer 6 remains something of an enigma. Some of the cells in this layer receive direct thalamo-cortical input, placing layer 6 with layer 4 as a sensory input layer. It is also, however, an important output layer,

Abbreviations:A1, primary auditorycortex;AMPA, $\alpha$-amino-3-hydroxyl-5-methyl4-isoxazole-propionate; bHLH, basic helix-loop-helix [a transcription factor]; CASK, calcium/calmodulin-dependent serine protein kinase 3 [multidomain scaffolding protein with a role in synaptic transmembrane protein anchoring]; CC, corticocortical; CHL1, neural adhesion molecule close homolog of L1; CT, corticothalamic; EPSP, excitatory postsynaptic potential; GABA, $\gamma$-aminobutyric acid; GluR, glutamate receptor; mGluR, metabotropic glutamate receptor; neuroD2, neurogenic differentiation 2 [a neurogenic bHLH protein]; Npn1, Neuropilin1 [a semiphorin receptor]; NR2B, N-methyl-D-aspartate receptor type 2B; nRT, nucleus reticularis thalami or reticular nucleus of the thalamus; Pom, posterior thalamic group; S1/Sm1, primary somatosensory cortex; Tbr1, a neurone-specific T-box transcription factor; $\mathrm{V} 1$, primary visual cortex; $\mathrm{VB}$, ventrobasal nucleus of the thalamus; VPm, ventral posteromedial nucleus of the thalamus from which large descending projections to many thalamic nuclei arise. Moreover, the several subclasses of corticothalamic neurones constitute only some $30-50 \%$ of the pyramidal cells in layer 6 . Layer 6 corticocortical (CC) cells form another large group of pyramidal cells that send long horizontal axons which form connections across cortical columns and cortical areas, eg. somatosensory and motor. The fourth major class of pyramidal cells projects to the claustrum in addition to sending long horizontal axons through the deep cortical layers. At the end of each section is a summary in italics.

\section{A NOTE ON NOMENCLATURE}

In the literature, discussion of different regions of thalamus uses the terms primary sensory, or 'specific' to describe the thalamic nuclei or regions that receive direct excitatory input from the periphery, eg. from the retina, or from the trigeminal nucleus. Regions that receive sensory input indirectly, via the cortex, have often been rather loosely termed 'non-specific' or association regions. In this review, the term 'primary sensory' is used to describe those thalamic regions that receive sensory input directly from the periphery. Similarly, to assist those less familiar with the cytoarchitectonically identifiable regions of sensory and association cortex, the term primary sensory cortex is used broadly here to describe those regions that receive thalamo-cortical input from primary sensory regions of thalamus, eg. V1 (primary visual cortex, Brodmann's area 17), SmI (or SI, somatosensory, areas 1-3), or AI (auditory, areas 41,42). Secondary sensory refers to those cortical regions that receive sensory information directly from primary regions and association regions of cortex, rather loosely to define cortical regions that receive sensory information via cortex and 'non-specific', or association thalamus.

\section{DEVELOPMENT OF LAYER 6 EARLY DEVELOPMENTAL DIFFERENTIATION OF CORTICOCORTICAL AND CORTICOTHALAMIC PYRAMIDAL CELLS IN LAYER 6}

Early data from spontaneous mouse mutants indicated that the basic neuronal phenotype reflects the birth-date of a neurone, relatively independently of its subsequent laminar position. In a review 
of these data, Caviness and Rakic (1978) concluded that neurones attract appropriate thalamic input rather than being equipotent on their birthday and then specified, as one type of cell or another later, by the type(s) of input they receive. Layer 6 is the first neocortical layer to develop (Rakic, 2009, for an excellent review of cortical development) and the cortico-thalamic (CT) pyramidal cells of layer 6 may be the earliest pyramidal cells to populate the developing neocortex (for distinctive features of CT and CC cells in adult cortex see below and Figure 1).

Pyramidal and spiny stellate cells are born in the ventricular zone and to reach their destination in the cortex, they are first guided to the cortical plate. Here, later born cells destined for more superficial layers, must pass the earlier born neurones of the deep layers as they migrate radially to their final positions. The finding that the cortex develops 'inside out' in mice lacking the Reeler gene (reln) prompted a large body of work on the development of cortical lamination and the involvement of the secreted signal, Reelin, its receptors and their downstream signalling pathways that control/promote both the migration and termination of migration (Huang, 2009; Rakic, 2009, for reviews). Unlike pyramidal cells, cortical interneurones are born in the medial and caudal ganglionic eminence (MGE and CGE) in the ventral forebrain and, in primates, in the subventricular zone. From these regions they migrate tangentially through the cortical marginal zone and along the subventricular/intermediate zone, to reach their final positions by radial migration within the cortex.

The selective expression by the L6 CC pyramidal cells, of latexin (a carboxypeptidase A inhibitor: Arimatsu et al., 1999a, expressed predominantly by glutamatergic neurones, Arimatsu et al., 1999b) allows two major pyramidal cell classes, CC and CT, to be distinguished during embryonic and postnatal development. The CT cells of the second somatosensory cortex of the rat are born earlier (on or before embryonic day 14, E14) than the CC cells (on or after E15) (Arimatsu and Ishida, 2002). Regional target preferences of these two cell classes have also been explored in co-culture studies in which the latexin-positive, CC cell axons readily invaded and innervated explants of other cortical regions, but failed even to invade dorsal thalamic explants. These thalamic explants were, however, readily innervated by co-cultured, latexin-negative CT cell axons (Arimatsu and Ishida, 2002). Latexin-positive CC cells are reported to contribute to so called 'feed-back' connections from sensory association cortical areas to primary sensory cortical regions, but rarely to 'feed-forward' callosal or intra-hemispheric connections (Bai et al., 2004).

It therefore appears that whether the axon of a layer 6 pyramidal cell will, as the cell develops, project subcortically and innervate the thalamus, or whether it will remain confined to the cortex and form long horizontal corticocortical connections, is determined at- and even possibly by-the time of the neurone's birth, before it migrates to the primordial cortex.

\section{THALAMOCORTICAL PATHWAY DEVELOPMENT}

Many of the first neurones of the embryonic cortex are born in the subplate. They are the first cortical neurones to receive input from the thalamus, long before layer 4 develops, but most of them will disappear as the cortex matures (Friauf et al., 1990). Transient connections between afferent axons and subplate neurones help to guide subsequent innervation patterns, with the subplate acting as a substrate for competition, segregation, and growth of these afferents, those from the brain stem arriving first, then those from the basal forebrain, the thalamus and finally from the ipsi- and contra-lateral cerebral hemispheres. As these fibres enter the cortical plate, the subplate zone disappears, leaving just a few cells of subplate origin scattered within the subcortical white matter (Kostovic and Rakic, 1990).

How the ordered, topographically precise targeting of thalamic fibres, from primary sensory thalamic nuclei to appropriate primary sensory regions of the neocortex, is controlled, is still a subject of intense interest. A wide range of cell-recognition and guidance molecules, such as the semaphorins, are fundamentally important here. Semaphorins are proteins, some membrane bound, some secreted, that inhibit the growth of axons that bear the appropriate receptor, deflecting them from regions rich in these proteins. For example, although thalamocortical pathways subserving other modalities appear to organise normally, axons from the LGN fail to innervate the developing visual cortex, at the appropriate time, in the absence of Semaphorin-6A. Visual cortex becomes innervated by somatosensory thalamic afferents instead. However, axons from the LGN do eventually reach the visual cortex, albeit via unconventional routes and successfully compete with those from somatosensory regions for postsynaptic targets (Little et al., 2009). This implies that final connectivity patterns are determined before and, to an extent, independently of, subplate sorting. It is, however, clear that the time at which each events occurs, in relation to others, is also critically important in the appropriate maturation of the brain and subplate sorting may play critical roles here.

Projections from the ventrobasal nucleus of the thalamus (VB) to the somatosensory cortex also utilize semaphorins. This pathway is disrupted by deletion of the Semaphorin 3A receptor Npn 1 (Neuropilin1), or a protein associated with Npn1-triggered growth cone collapse (CHL1, or neural adhesion molecule close homolog of L1). In Npn1 knockouts, axons from VB shifted caudally and innervated the visual cortex (Wright et al., 2007).

Early topographic sorting of thalamocortical axons, as they grow towards the cortex through the ventral telencephalon (future basal ganglia), requires Ephrins and their receptors. This molecular recognition system uses thalamic axon receptor- and cortical neurone ligand-expression and contributes to interareal topographic mapping of thalamocortical axons within the developing cortex (Dufour et al., 2003).

Subplate neurones are the first immature cortical neurones to appear and they form some of the earliest connections with subcortical structures, receiving, for example, the first synaptic inputs from the developing thalamus. Some controversy appears to surround precisely how important the subplate is in controlling the orderly arrangement of incoming and outgoing axons, since there is evidence that even originally misdirected axons can eventually reach their preordained targets. Whether all aspects of maturation proceed normally when this input is delayed, however, is unclear. Axon guidance molecules, particularly members of the semaphorin family are associated with the orderly arrangements of thalamic afferents as they invade the developing cortex, deflecting growth cones from inappropriate paths. 


\section{CORTICOTHALAMIC CELL PATHWAY DEVELOPMENT}

The subplate also appears to play a role in guiding cortical efferents, some subplate neurones acting as pioneers for pathways such as the corticothalamic pathway (McConnell et al., 1989). However, the numbers of subplate and layer 6 neurones retrogradely labelled from the thalamus are very low at E43-44 in the ferret, when a powerful projection from layer 5 is already invading the thalamus. The subplate and upper layer 6 neurones have migrated to their final positions by E36 (a few days before birth, gestation lasts 38-44 days in the domestic ferret), but wait for another 2-3 weeks before projecting beyond these regions. Over the next few days to weeks, these cells innervate their final target regions and eventually, the descending projection from layer 6 CT cells overtakes the layer 5 innervation of the thalamus (Clascá et al., 1995). The projections from these two layers are, of course, also differently distributed in the mature cortex (see below and Figure 4).

Within the cortex, the local axonal arbours of the layer 6 CT cells also continue to develop slowly, barely invading layer 5 by P13-15 in the ferret and continuing to branch in layer 4 up to P35 (Callaway and Lieber, 1996). For those more familiar with kitten/cat development, the critical period, which lasts from week 4 to 6 in the kitten visual cortex, peaks later in the ferret, between postnatal weeks 5 and 8 (Issa et al., 1999). The sublayer-specific ramifications of layer 6 CT cell axons in layer 4 (Wiser and Callaway, 1997, see also Figure 3 ) therefore approach mature distributions during the critical period.

In mice, CT cell axons reach and invade the thalamus between E14 and 15, with subplate neurones being the first to arrive, a day or two later than the thalamic fibres reach the cortex. By E20, ie. at birth, thalamocortical relay cell axons have branched extensively in the deep cortical layers (Auladell et al., 2000). In mouse somatosensory cortex, a $\mathrm{Ca}^{2+}$-regulated basic helix-loop-helix (bHLH) transcription factor, Neurogenic Differentiation 2 (neuroD2), is required for the appropriate segregation of the terminal arbours of layer 6 CT cell axons within layer 4 barrels. In neuroD2-null mice, barrel organization is disrupted and synaptic transmission is defective (Ince-Dunn et al., 2006).

A range of transcription factors are also involved in regulating the descending projections from CT cells. It appears that the transcription factor SOX5 is required for the down-regulation, in the subplate and in layer 6, of Fezf2 and Bcl11b. These zinc finger genes are transiently expressed in all newly postmigratory early-born neurones and their down-regulation is necessary for the maturation of layer 6 neurones and for establishing their mature axonal projection patterns. Amongst other abnormalities, layer 6 neurones remain immature without SOX 5 and the axons of both subplate neurones and layer 6 CT cells become mis-directed to the hypothalamus (Kwan et al., 2008). Fezf2 and Ctip2, the transcription factor that is its major down-stream effector, regulate the projections, whether corticocortical or subcortical, of deep layer neurones (Shimizu and Hibi, 2009). Tbr1 (a transcription factor that interacts with CASK and regulates reelin expression) is highly expressed in early-born glutamatergic cortical neurones, like those of layer 6. Mice that are deficient in Tbr1, in addition to decreased expression of Reelin and a reeler-like cortical migration disorder, demonstrate errors in the thalamocortical, corticothalamic, and callosal projections (Hevner et al., 2001).
Although neurones have arrived in the subplate and in layer 6 before layer 5 begins to develop, at first the axons from layer 5 innervate the developing thalamus more densely, being overtaken by layer 6 CT cell axons only later. The local axonal arbours of layer 6 cells are also relatively slow to develop, reaching fully mature ramifications and sublayer specificity during the postnatal critical period. A number of transcription factors have been shown to regulate the maturation of layer 6 neurones and the organisation of their cortical and subcortical axonal projections. Without one or other of these factors, or their effectors, misdirection of pyramidal axons to inappropriate targets occurs.

\section{IDENTIFICATION OF MATURE LAYER 6 PYRAMIDAL CELL CLASSES STRUCTURAL CHARACTERISTICS OF THREE MAJOR CLASSES OF LAYER 6 PYRAMIDAL CELLS}

A detailed comparison of the layer 6 pyramidal cells that project to the thalamus (CT cells) and those that provide only corticocortical projections (CC cells) in rat somatosensory cortex, demonstrated that there are striking structural differences between these two broad cell classes. Put simply, CT cells are fairly short, upright pyramids with narrow local axonal arbours that project up towards more superficial layers, while CC cells include a range of atypical dendritic morphologies: inverted pyramids and bipolar cells as well as short upright pyramids. Unlike CT cells, CC cells have long, horizontally oriented axons that remain confined to the deep layers. From somatosensory cortex, for example, these branches project to the second somatosensory or motor cortices, or to the corpus callosum. Figure 1 summarises the main distinguishing features of the different classes of layer 6 pyramidal cells.

Layer 6 CT cells can be further sub-divided. For example, in rodent somatosensory cortex, those that project only to the primary sensory, ventral posteromedial nucleus of the thalamus (VPm) are found in upper layer 6 (Bourassa et al., 1995) and have a well developed apical dendritic tuft and a narrow, vertically oriented axonal arbour, with drumstick-like appendages, both of which terminate in layer 4 (Zhang and Deschênes, 1997). CT cells that project to the posterior thalamic group (Pom), which does not receive primary sensory input, as well as to the VPm are found in deep layer 6 . These are shorter upright pyramids with both their axons and their apical dendrites ramifying and terminating in layer 5 (Zhang and Deschênes, 1997). This sublayer selectivity in CT morphology and target selection, is seen in a wide range of species and in all primary sensory cortical regions. Simplistically, upper layer 6 CT cells selectively and therefore reciprocally innervate the region of primary sensory thalamus from which they receive direct input. These CT cells also innervate the GABAergic, inhibitory nucleus reticularis thalami (nRT, or reticular nucleus of the thalamus) (Bourassa and Deschênes, 1995), while the shorter, lower layer 6 CT cells innervate interlaminar nuclei and/or regions of association thalamus affiliated with the primary sensory modality, in addition to providing reciprocal innervation to primary sensory thalamic nuclei (Deschênes et al., 1998; Llano and Sherman, 2008, see also Figure 4). These shorter CT cells do not, however, innervate nRT. In cat visual cortex, some of these shorter CT cells with complex receptive fields, project to the supra-granular layers, ie. 


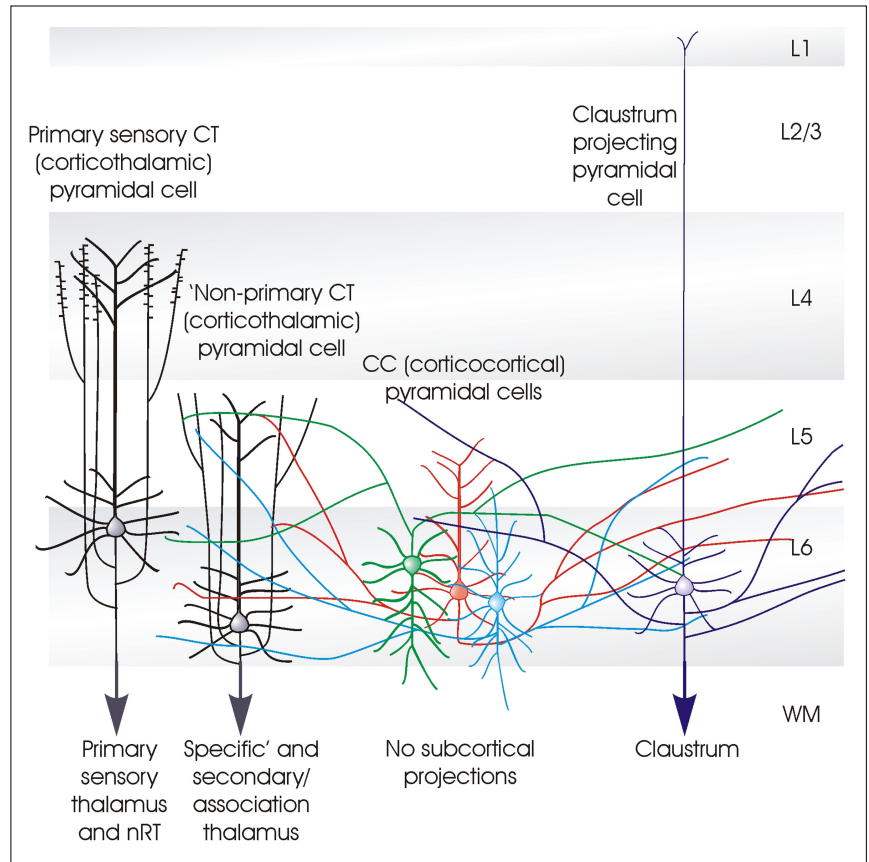

FIGURE 1 | Cartoon summarising some of the distinctive features of the different classes of layer $\mathbf{6}$ pyramidal cells. The term 'specific' is used here to identify the CT (corticothalamic) cells that project exclusively to primary sensory, or 'specific' thalamic nuclei (or regions) and to the (nRT). Both the apical dendrites of these 'specific' CT cells, and their axons ramify in layer 4. The axons of 'non-specific' CT cells ramify in layers 5 and 6 and sometimes in layers $2 / 3$. These shorter CT cells innervate both 'specific' and 'non-specific' or association regions of thalamus, but not the nRT. CC (cortico-cortical) pyramidal cells do not project below the cortex. Both their dendrites, which display a range of morphologies and their long horizontally oriented axonal arbours are confined to layers 5 and 6 . The axons of claustrum projecting pyramidal cells are also horizontally oriented and confined to the deep layers, but these cells have long slender apical dendrites that reach layer 1 with little branching.

layers 2 and 3, which, like layer 5, are rich in complex cells (Hirsch et al., 1998). They also project to ventral, rather than dorsal LGN and to the konicellular layers of the geniculate nucleus and to extra-geniculate thalamus (for reviews, see Lund, 1988; Fitzpatrick, 1996; Callaway, 1998). Another feature that distinguishes CT cells in primate V1 from their near neighbours is a significantly more dense innervation of their somata by inhibitory synapses (Lund et al., 2001)

A third group of layer 6 pyramidal cells that project to the visual claustrum was first identified in cat (similar morphologies have since been described in rat) by retrograde labelling with fluorescent latex microspheres and were found to differ from both CT and $\mathrm{CC}$ cells in their dendritic and axonal arborizations. Claustrumprojecting cell axons resembled those of CC cells, with long, fine, horizontal projections largely confined to layer 6 and lower layer 5 . However, unlike other layer 6 cells, claustrum projecting pyramidal cells have very long, slender apical dendrites that reach layer 1 , with little if any branching in layer 4 and at best a meagre apical tuft (Katz, 1987) (for morphometric analysis of Golgi-labelled layer 6 neurones see: Chen et al., 2009).

These structural differences have allowed the three major classes of layer 6 pyramids, CT, CC and claustrum-projecting cells, to be identified following dye-labelling during in vitro recordings, at least tentatively. Since major differences in the physiology of the cells and their synaptic connections have been identified, this differentiation has proved extremely valuable.

There are three major classes of layer 6 pyramidal cells that can be distinguished by the shapes of their axonal and dendritic arbours; the upright corticothalamic or CT cells with vertically oriented axons that ascend to layer 4 or 5 and a well developed apical dendritic tuft in layer 4 or 5; the CC cells which come in a range of different shapes from short upright pyramids, to bipolar cells with axons that do not leave the cortex, or, typically, ascend above layer 5, but extend for long distances horizontally and the claustrum projecting pyramids with a long slender apical dendrite and long horizontally oriented axons confined to the deep layers.

\section{THE ELECTROPHYSIOLOGICAL CHARACTERISTICS OF LAYER 6 PYRAMIDAL CELLS CORRELATE WITH THEIR STRUCTURAL SUBTYPE.}

The electrophysiological properties of CC and CT cells differ sufficiently to allow them to be distinguished in healthy mature preparations. CC cells have a strongly phasic response to square-wave depolarizing current injection. One to three, short interval spikes are elicited at the start of a depolarizing pulse, but additional current elicits no further firing. For those more familiar with the hippocampus, these responses somewhat resemble those of the granule cells of the dentate gyrus. A large, systematic study correlating physiology and morphology has not yet been performed and it is possible that more subtle differences between for example, bipolar, inverted and upright CC cells may emerge. However, as a broad class, almost all CC cells and indeed all claustrum projecting cells subsequently identified morphologically, displayed this very strongly adapting electrophysiological signature.

In striking contrast, CT cells have a near tonic firing pattern. They display some spike frequency adaptation in response to prolonged depolarization, but typically, do not cease firing while the cell is above firing threshold. Interestingly, the firing properties of these two broad classes of layer 6 pyramidal cells and the short term dynamics of their synaptic outputs could combine to ensure a powerfully phasic output from CC cells, but a maintained, or even, at some outputs, an augmenting response at CT cell outputs (see below and Mercer et al., 2005).

Electrophysiologically, both CC cells and claustrum projecting cells display powerful spike frequency adaptation in response to maintained depolarization. In contrast, CT cells display a weakly adapting firing pattern, maintaining near tonic firing. In mature preparations, these characteristics allow neurones to be tentatively identified during intracellular recordings.

\section{INPUTS TO LAYER 6}

In a retrograde labelling study, the most profuse, longer distance, cortical inputs to layer 6 of the whisker barrel field (part of primary somatosensory cortex in rodents) came from motor cortex, with sparser inputs provided by other cortical somatosensory regions, thalamic afferents (from VPm, Pom and the intralaminar nuclei) and the claustrum (Zhang and Deschênes, 1998).

\section{LOCAL CIRCUIT CONNECTIONS TO LAYER 6 NEURONES}

In rat thalamo-cortical slices, electrical stimulation in the thalamus elicited short and long latency monosynaptic EPSPs (excitatory postsynaptic potentials) in layer 6 pyramidal cells and interneurones. The 
EPSPs elicited in interneurones being larger than those in pyramidal cells. The short latency events, concluded to be due to the thicker, more rapidly conducting thalamocortical inputs, exhibited paired pulse depression, while the presumed local circuit inputs, from antidromically activated CT cells, exhibited paired pulse facilitation. A small population of EPSPs, studied using paired recordings in layer 6, all exhibited paired pulse depression, leading the authors to conclude that local connections made by CT and CC cells may exhibit different short term synaptic dynamics (Beierlein and Connors, 2002).

This difference between CC and CT outputs was confirmed with dual intracellular recordings in adult rat and cat layer 6 , in which the pre- and post-synaptic cells were labelled with biocytin/HRP and therefore identifiable (Mercer et al., 2005; West et al., 2006). All connections made by the axons of presynaptic CT pyramidal cells, whether onto another pyramid, or onto an interneurone, exhibited facilitation. This is highly unusual for pyramidal outputs. In all other layers, pyramid to pyramid connections 'depress' (eg. Thomson et al., 1993; Thomson, 1997; Thomson, Bannister, 1999) as do pyramidal inputs onto several classes of interneurones, including many of those that are immuno-positive for parvalbumin or CCK (eg. Thomson et al., 2002; Ali et al., 2007; Bannister and Thomson, 2007) and those that are immuno-positive for VIP (vasoactive intestinal polypeptide) (Porter et al., 1998). More typically, the only strongly facilitating outputs of pyramidal cells are those onto specific subclasses of interneurones (Deuchars and Thomson, 1995; Thomson et al., 1995; Markram et al., 1998), such as those that are immuno-positive for somatostatin (Kawaguchi and Kubota, 1996). In contrast, the local circuit outputs of layer 6 CC pyramidal cells onto other pyramidal cells and the two connections onto interneurones recorded, as well as the outputs of claustrum projecting pyramids, were all depressing (Mercer et al., 2005). Fluctuation analysis demonstrated that both the facilitation and depression observed were of presynaptic origin, ie. due to a change in release probability ' $p$ ' (West et al., 2006).

It was also possible to demonstrate that a binomial model of release described these connections well and to compare the binomial parameters, ' $p$ ', ' $q$ ' (quantal amplitude) and ' $n$ ' (number of release sites) obtained from fits of the model to experimental data, for different types of cortical connections (Brémaud et al., 2007). Pyramid to pyramid connections in layer 6 made by CC and CT axons, had very similar quantal amplitudes $(0.37 \mathrm{mV} \pm 11 \mathrm{mV}$ vs $0.37 \pm 0.18 \mathrm{mV}$ ), which were smaller than those in layer 3 and layer 5, but larger than those in layer 4 in rat. However, CT and CC outputs produced significantly different estimates for ' $n$ ' (CC $9.9 \pm 12.6 \mathrm{mV}$ vs. CT $2.7 \pm 1.3$ ) and ' $p$ ' (CC $0.61 \pm 0.14$ vs. CT $0.28 \pm 0.03)$.

In summary, CC pyramids innervate other pyramids much more frequently $(>4 X)$ than CT cells do. The connections made by CC cell axons with their near neighbours involve larger numbers of release sites that, at low frequencies, release transmitter with a higher probability and therefore display paired pulse and brief train depression. The outputs of CT cells onto other pyramids typically utilise fewer release sites and, with a lower release probability at low frequencies, exhibit facilitation.

Another striking difference between the connections made by CC and CT cell axons was their target preference. CT cells rarely innervated other pyramidal cells, while CC cells rarely innervated interneurones. Claustrum projecting pyramidal cells appeared to resemble CC cells in these respects, preferentially innervating pyramidal cells. The differences were not due simply to the amount of axon in layer 6, despite the profound differences in axonal arbour shape and the differences in the total length of axon in layer 6 for these cells classes. The total length of axon within the virtual sphere in which the cell pairs were recorded was not significantly different between the classes (Mercer et al., 2005). This degree of selectivity in target choice has not previously been described for intra-laminar connections in other layers. It has been reported for inter-laminar connections. For example, layer 3 pyramidal cells innervate layer 4 interneurones almost as commonly as layer 4 spiny cells do, but layer 3 pyramidal cells rarely, if ever, innervate layer 4 spiny cells (pyramidal and spiny stellate cells) (Thomson et al., 2002; Bannister and Thomson, 2007). A similar pattern is apparent in connections between layer 3 and 5 (see Thomson and Bannister, 1998; Thomson and Lamy, 2007, for review).

Layer 6 CC cells and claustrum projecting cells innervate layer 6 pyramidal cells of all classes with a relatively high 'hit rate'. They very rarely innervate layer 6 interneurones, however. The opposite is true for layer 6 CT cells which rarely innervate other layer 6 pyramids, but frequently innervate inhibitory interneurones.

\section{CONNECTIONS TO LAYER 6 FROM OTHER CORTICAL LAYERS}

Unlike layers 3, 4 or 5, layer 6 does not receive elaborate, focussed axonal arbours from spiny, excitatory cells in other layers. Instead, the descending axons of many layer 3 and layer 4 pyramidal cells traverse layer 6 with little or no branching, while the sparse, but very long, horizontally oriented axons of deep layer pyramids provide substantial opportunities for cross-columnar and inter-areal connections within the deep layers. The simple predictions that might be drawn from the above, ie. that layers 2, 3 and 4, would provide only a small and narrowly focussed excitatory input to layer 6 , while layers 5 and 6 would provide a more powerful and possibly laterally extensive input, are, to a large extent, borne out by functional studies (see Figure 2).

In a caged glutamate study in which the inputs to single dye-filled layer 6 neurones were activated, Zarrinpar and Callaway (2006) documented the laminar profiles of inputs to layer 6. Pyramidal cells whose dendritic arbours resembled those of upper layer 6 CT cells, ie. the pyramidal cells that project to primary sensory thalamic regions, received inputs from layers $4,5 \mathrm{~B}$ and 6 . Short, tufted, upright pyramids (ie. CT cells that may also project to thalamic regions that do not receive primary sensory input) received the majority of their excitatory input from within layer 6, with only a minor component from 5B. CC cells also appeared to receive almost all their inputs from the deep layers: inverted pyramids near exclusively from layer 6 , bipolar cells from layer $5 \mathrm{~A}, 5 \mathrm{~B}$ and 6 , with a very small input from layer 4 , while non-tufted putative upright CC cells received minor inputs from layer $2 / 3$, a very small input from layer 4 , but again, their major excitatory inputs came from layers 5 and 6. Layer 6 multipolar interneurones also received most of their excitatory input from within layer 6 , but some input, indeed more than to any other layer 6 cells, came from layer $2 / 3$. Although the layer, or even the sub-layer of origin of cortical inputs to identified target neurones can be relatively clearly distinguished with this approach, the class(es) of presynaptic cell(s) involved 


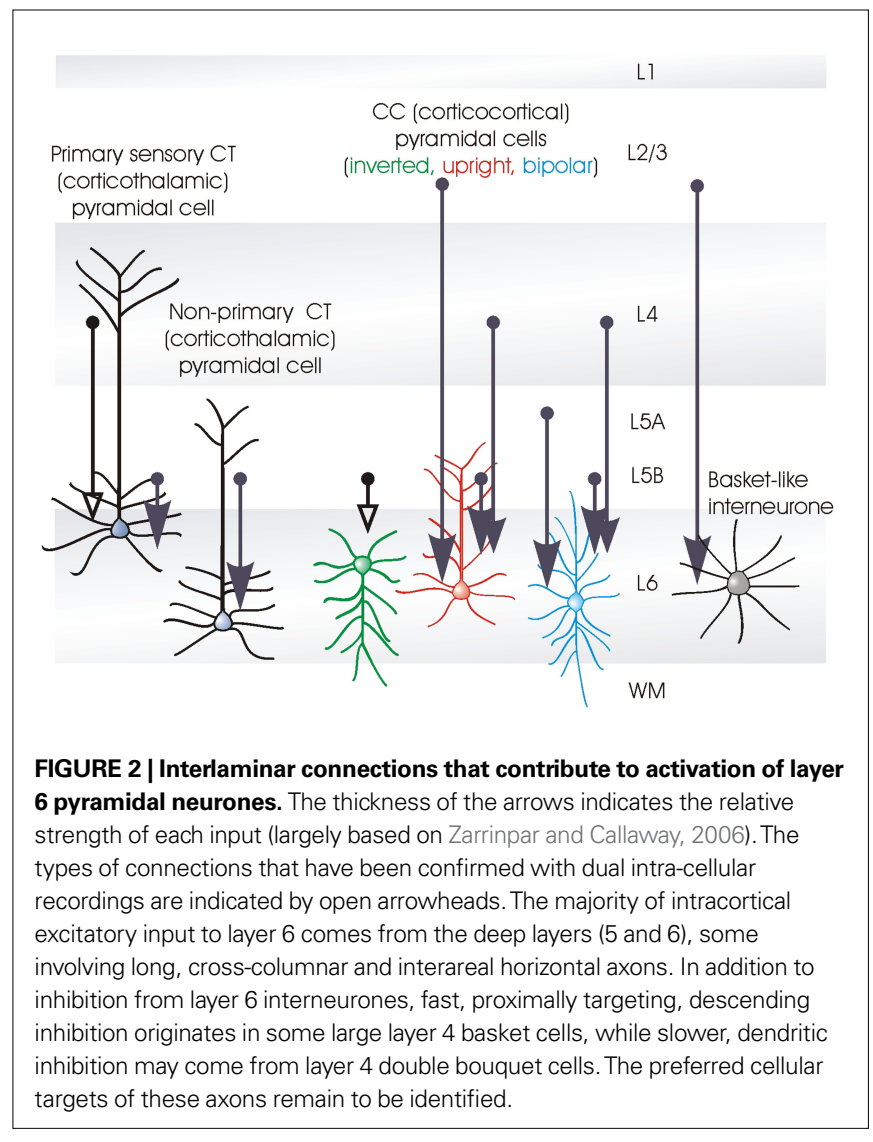

cannot be unambiguously identified. In some cases, probable cellular source(s) of a given input can be surmised by correlating with other studies, but unless both neurones are unambiguously identified, uncertainty remains.

Unambiguous identification requires dye-filling and full reconstruction. This has only rarely been achieved for inter-laminar connections involving layer 6 and the only published examples are for inputs to layer 6 from layer 5 (Mercer et al., 2005). In that study, two layer 5 pyramid to layer 6 pyramid pairs were described (one in cat, one in rat). The postsynaptic cells were both inverted CC-like pyramidal cells in layer 6 and the presynaptic layer 5 cells were a small adapting pyramidal cell (in cat) and a large tufted, intrinsically burst firing pyramidal cell (in rat). The sample was too small to allow 'hit rates' to be estimated, but the impression gained was that this is a relatively common type of connection - possibly as common as intralaminar layer 6 pyramid-pyramid connections. Clearly, however, these existing studies need to be extended considerably to explore the relative strengths of inputs from different types of layer 5 cells to different types of layer 6 cells.

The long receptive fields, that are typical of a proportion of pyramidal cells in layer 6 of primary visual cortex (area V1) (eg. McGuire et al., 1984), have been proposed to result from the properties of presynaptic layer 5 cells and their projections to layer 6 . When layer 5 was blocked very locally with GABA application, layer 6 cells lost the component of their receptive fields that corresponded in visual space with the inactivated region of layer 5. This effect was maintained with horizontal displacements of up to $3 \mathrm{~mm}$ (Bolz and Gilbert, 1989). Cross-correlation stud- ies suggested that layer 6 cells and co-oriented, coaxially aligned standard complex layer 5 cells, some displaced several millimetres laterally, receive common input, though the origin of that input was unknown. It was proposed that if direct connections from these layer 5 cells also exist, this topographic arrangement and the length summation properties of the layer 5 cells could be well suited to generate the long receptive fields typical of some layer 6 cells (Schwarz and Bolz, 1991). Clearly, layer 5 does provide significant input to layer 6 . Whether the targets in layer 6 of the laterally displaced layer 5 cells are CC or CT cells, or indeed whether it is the CC, or the CT cells, or both, that have long receptive fields remains unclear.

\section{The position of layer 6 cells in the cortical circuit}

A number of interesting uncertainties arise from these previous studies and by analogy with other cortical layers. The demonstrable local connectivity associated with layer 4 pyramidal and spiny stellate cells results in a simple proposal. Layer 4 spiny cells are directly thalamorecipient and their response properties are similar in many ways to those of their presynaptic thalamic relay cells. Given this, it is perhaps not surprising that layer 4 cells do not receive a significant and potentially 'contaminating' input from layer 3 pyramidal cells, since layer 3 cells have very different response properties, requiring more complex stimuli for a brisk response. The simplicity of first order, layer 4 cell response properties appears to be preserved by the channelling of sensory information in one direction, from layer 4 to layer 3 and from layer 3 to layer 5 and not back again. From layer 5, a highly processed signal is then sent out to subcortical structures.

What then of layer 6 CT cells? They, like layer 4 spiny cells, are first order, thalamo-recipient cells. Again, like V1 layer 4 cells, many upper layer 6 CT cells appear to be simple cells. But they are also output neurones. Their position in the local circuit is similarly ambiguous. They do not receive the equivalent of the powerful, unidirectional 'columnar' input from a single other layer - like that from layer 4 to 3, or from layer 3 to 5. Their inputs from all layers but 5 and 6 appear to be relatively weak, while their input from layer 5 appears to be spatially diffuse. As far as we understand it, therefore, their place in the cortical circuit predicts that layer 6 CT cells integrate already highly processed information, from layer 5 pyramids and from layer 6 CC cells, with the direct input they receive from the thalamus.

\section{INHIBITORY INPUTS TO AND FROM LAYER 6}

In contrast to the relatively weak excitatory input from layer 4 to 6 , there appears to be a relatively strong inhibitory input. Just as some of the large layer 3 interneurones send an axon collateral to layer 5 , where a secondary arbour forms, large layer 4 basket cells relatively frequently have an axonal arbour in layer 6 , in addition to their $\operatorname{arbour}(\mathrm{s})$ in layer 4 . In some cases the axon ramifies in layer 5 en route, in others, the arborisation is much stronger in layer 6 (see also Lund and Yoshioka, 1991). These interneurones include large layer 4 basket cells with a fast spiking firing pattern, a large myelinated descending axon and somatic or proximal dendritic targets. Layer 4 double bouquet cells (Somogyi and Cowey, 1981) with an adapting firing pattern, a bundle of fine descending unmyelintated axons and more distal dendritic targets, also innervate layer 6 . 
These inhibitory connections are reciprocal, layer 5 interneurones projecting to layer 3, while layer 6 interneurones project to layer 4 (Lund et al., 1988). Large basket cells are, again, one of the major classes of layer 6 interneurones that project to layer 4, with layer 6 Martinotti cells probably forming the major class of more distal dendrite-targeting interneurone with an ascending axonal arbour and innervating all layers from 6 to 1 . Interneurones that innervate both layers 6 and 5 are also common.

We are far from understanding the roles played by the many different classes of inhibitory interneurones in the neocortex and detailed discussion of this issue is beyond the scope of this review. It is however interesting that the two thalamo-recipient layers, 4 and 6, like the two layers ( 3 and 5) that are rich in complex cells (in V1), are linked by the axonal arbours of large basket cells. The near simultaneous, fast and powerful inhibition in layers 4 and 6, provided by these multi-laminar large basket cells, will promote synchrony between these thalamo-recipient layers; a synchrony that will be strongly influenced by thalamo-cortical input, since these parvalbumin-containing layer 4 interneurones are a major class of inhibitory cells innervated by thalamic afferents (Staiger et al., 1996b). It should also be remembered that the inhibition provided by layer 6 interneurones, including those that link layers 4 and 6 , is very much more strongly influenced by first order CT cells than by potentially higher order CC cells. This influence, will not, however, activate these interneurones rapidly, since these layer 6 CT cell to interneurone connections are facilitating. It might, however, prolong the responses of these interneuones if they also, like those in layer 4, are directly thalamo-recipient and receive depressing inputs from these axons.

\section{INTRACORTICAL OUTPUTS OF LAYER 6 CONNECTIONS FROM LAYER 6 TO 4}

Although a number of anatomical studies have described the - often quite dense - axonal arbours of layer 6 CT cells in layer 4 , very few have documented the properties of the connections formed there, or even the relative numbers of different types of postsynaptic targets in layer 4 . In a caged glutamate study in slices of rat somatosensory cortex, layer 4 pyramidal cells were shown to receive excitatory inputs from layers 4,5 and 6 , although the inputs from the deep layers were substantially weaker than those from within layer 4 . Layer 4 spiny stellate cells, moreover, received intra-columnar excitatory input almost exclusively from layer 4 (Schubert et al., 2003).

One dual intracellular recording study in slices of cat visual cortex described seven layer 6 to 4 connections involving a presynaptic CT cell and a postsynaptic pyramidal or spiny stellate cell. The EPSPs generated were smaller (around $0.2 \mathrm{mV}$ in average amplitude) than those of connections between layer 4 spiny cells $(0.9 \mathrm{mV})$ and, unlike layer 4 intralaminar connections, but like the other outputs of CT pyramids, exhibited paired pulse facilitation (Tarczy-Hornoch et al., 1999). Interestingly these layer 4 synapses share another property of synapses made by CT cell axons that was first described in thalamus (see below), the activation of postsynaptic group 1 metabotropic receptors (mGluR). In slices of auditory and somatosensory cortex, electrical- or photo-stimulation of layer 6 elicited a prolonged depolarization mediated by these receptors (Lee and Sherman, 2009).

\section{LAYER 4 TARGETS OF PRESYNAPTIC LAYER 6 CT CELLS}

It is unclear whether the apparent functional weakness of the projection from layer 6 to 4 results from a true functional weakness, or from axons being cut during slicing. In none of the published pairs were both neurones recovered histologically, so that the relative position of the postsynaptic neurone within the presynaptic axonal arbour is unknown. It is also possible that layer 4 interneurones constitute a major target for layer 6 CT axons. This was strongly suggested by an ultrastructural analysis of the postsynaptic targets of HRP-filled layer 6 pyramidal cells in cat striate cortex. The majority of targets were dendritic shafts belonging to smooth or sparsely spiny layer 4 cells, suggesting that inhibitory interneurones contribute a significant proportion of the postsynaptic population. The smooth dendritic targets included both beaded and nonbeaded profiles and the majority of synapses were made by bouton terminaux from the side twigs typical of these axons (McGuire et al., 1984). In contrast, however, in an ultrastructural study of rat somatosensory CT cell axons that had been retrogradely labelled from the primary sensory thalamic VPm nucleus, only a minority (14\%) of the targets in layers 4 and 5 were immuno-positive for GABA (Staiger et al., 1996a). The other targets were GABA-negative dendritic spines (55\%) and shafts (31\%) (see also: Anderson et al., 1994). Whether this difference is due to species, regional, or methodological differences remains to be determined.

The role that layer 6 plays in shaping the responses of layer 4 cells to sensory input continues to be controversial (see length-tuning, below). That layer 6 CT cells provide a significant input to layer 4 is clear. It is also clear that this input will not generate rapid layer 4 cell activation (or indeed, inhibition) at the very beginning of a response to a novel stimulus, since all inputs mediated by layer 6 CT cells are low probability at low frequencies, facilitating on repetitive activation. It is possible that layer 6 mediates, or modulates, some of the later components of layer 4 responses to novel sensory stimuli, since layer 4 responses to thalamic input can be powerful and fast, but depress strongly.

\section{LAYER 6 TO LAYER 5}

Like the reverse connection from layer 5 to 6 , layer 6 CC cells appear to provide a significant excitatory input to layer 5 pyramidal cells. In a paired recording study (Mercer et al., 2005) two such connections were recorded, one to a small layer 5 pyramid in rat and one to a large layer 5 pyramid in cat. Both were relatively powerful $(>1 \mathrm{mV}$ average amplitude) and exhibited presynaptically mediated paired pulse and brief train depression.

\section{INPUTS TO LAYER 6 CELLS FROM THE THALAMUS RECEPTIVE FIELD PROPERTIES}

When compared with studies of layer 4 and more superficial layers, relatively few studies have recorded responses of layer 6 cells to sensory input. Fewer still have been able to identify the neurones recorded. Visual cortical neurones described as simple cells, ie. those in which excitatory and inhibitory components of the receptive field do not overlap in visual space, are reported to reside almost exclusively in thalamo-recipient layer 4 and upper layer 6 . In lower layer 6 and layers 2, 3 and 5, complex cells were more common (Martinez et al., 2005). Since simple cells are most commonly found in the thalamo-recipient layers and their response properties are closer to 
those of 'specific' thalamic relay cells than are those of other cortical neurones, many layer 4 and upper layer 6 spiny cells can be assumed to be in receipt of direct primary sensory thalamo-cortical input. Lower layer 6, CT cells and perhaps all CC cells, like pyramidal cells in layers 2, 3 and 5, are more likely to receive less direct, integrated sensory information via both local cortical circuits and via thalamic cells that do not themselves receive direct peripheral input. This may correlate with the outputs of the different classes of layer 6 cells, with complex short CT and CC cells targeting layer 5 and in some cases, layers 2 and 3, layers that are rich in complex cells, while simple CT cells that receive direct primary sensory input from thalamus, target layer 4 , which is rich in simple cells (see above).

\section{INPUTS TO LAYER 6 FROM THE THALAMUS}

Thalamo-cortical inputs from primary sensory thalamic regions, like the VPm barreloids, to whisker barrels in the somatosensory barrel cortex, remain discrete. They do not enter the septa between barrels, nor do they innervate barrels associated with other whiskers and they terminate quite selectively in 'thalamo-recipient' layer 4, lower layer 3 and layer 6. In contrast, inputs from Pom (an association thalamic nucleus), terminate in inter-barrel septa and in all layers from upper L5 to L1. Moreover, these axons branch and innervate widely separated cortical regions (eg. sensorimotor or Sm cortex and frontal cortex). In primary sensory regions, layers that are not typically considered to be 'thalamo-recipient' (layers 1, 2, upper layer 3 and layer 5) receive input from regions of thalamus variously described as non-specific, secondary or association regions ie. regions that do not receive direct peripheral sensory input. In some cases entire nuclei can be defined either as primary sensory or not. In others, different sub-divisions of a single nucleus, eg. the LGN, play these different roles, the calbindin immuno-reactive cells (in primate) contributing to secondary or association thalamus, or matrix, and the parvalbumin immuno-reactive cells contributing to the primary sensory, or core regions (Jones, 1998). Thus, the more proximal dendrites of layer 6 neurones, within L6, are positioned to receive direct, focussed input from a topographically appropriate region of primary sensory thalamus, eg. the appropriate VPm barreloid. Whether their more distal dendrites in layer 5 receive input from secondary or association regions, such as Pom, whose relay cell axons terminate in layer 5 (Deschênes et al., 1998), and/or whether $\mathrm{CC}$ or claustrum-projecting cells receive this input, remains to be explored. The excitatory inputs to the distal dendritic tufts, in layer 4 , of primary sensory CT cells also remain to be fully elucidated, but it is likely to originate with primary sensory thalamic afferents and/or thalamo-recipient layer 4 spiny cells.

The existence of parallel information-processing streams (Nassi and Callaway, 2009) is perhaps more apparent in layer 6, than in any other layer. The major pyramidal cell classes : CC cells, CT cells associated with primary sensory thalamic nuclei, CT cells associated with secondary or association thalamic regions, and claustrum projecting cells, have different relationships with a range of thalamo-cortical and cortical inputs, as well as different outputs within the local circuit, across different regions of cortex and in subcortical regions. The extent to which these streams interact functionally is not known in detail, but interactions are apparent, for example, in the relatively dense innervation of all layer 6 pyramidal cells by layer 6 CC cells and by layer 5 pyramidal cells.

\section{CORTICOTHALAMIC OUTPUTS}

To make any sense of the possible function(s) of layer 6 CT cells, some understanding of its complex interactions with the thalamus is necessary. This is, however, a complex system that is difficult to study and the influences that layer 6 has on thalamic function have become somewhat controversial.

\section{PROPERTIES OF CORTICOTHALAMIC SYNAPSES IN SPECIFIC SENSORY THALAMIC NUCLEI}

LGN relay cells receive large, fast, secure AMPA-receptor- and NMDA-receptor-mediated EPSPs from the retina, via large, proximally located synapses (Jones and Powell, 1969), some of which are glomerular (Mason et al., 1984). These connections exhibit paired pulse depression. In contrast, the more distally activated (Sherman and Guillery, 1996), smaller, slower EPSPs generated by CT cells in primary sensory thalamic nuclei (Landisman and Connors, 2007), involve a large NR2B-mediated component with slower kinetics, possibly a kainate receptor (GluR5) component (Miyata and Imoto, 2006) and an mGluR1-mediated component, in adult (Turner and Salt, 1998) and in juvenile rat LGN slices (Hughes et al., 2004; Reichova and Sherman, 2004). Activation associated with GluR5 may also result from disinhibition via GluR5 receptors located on GABAergic nRT axon terminals (Godwin et al., 1996; Binns et al., 2003). Presynaptic mGluR2 receptors activated during repetitive CT firing appear to reduce facilitating relay cell responses to trains of cortico-thalamic spikes (Alexander and Godwin, 2005). These inputs from cortex display paired pulse facilitation in juvenile rat LGN thalamo-cortical slices (Granseth et al., 2002) and adult mouse VB (ventrobasal thalamic nucleus) slices (Castro-Alamancos, 2002). Although paired pulse and brief train facilitation were apparent in both, they were more pronounced in cortico-thalamic EPSPs in ferret LGN relay cells than in the visual division of the inhibitory nRT nucleus, the perigeniculate (Alexander et al., 2006), while the cortico-thalamic inputs to nRT cells in juvenile mice were substantially more powerful, involving 3-4 times the number of receptors (Golshani et al., 2001). All the connections from CT cell axons studied to date have, unusually for cortical pyramidal cells, generated facilitating EPSPs, whatever the class of target cell involved, though with differences in degree and expression of augmentation (Tarczy-Hornoch et al., 1999; West et al., 2006). How the properties and distribution of the cortico-thalamic inputs may influence the impact of cortical 'feedback' to the thalamus is explored in a multicompartmental model in Emri et al. (2003).

\section{PATTERNS OF CORTICOTHALAMIC INNERVATION}

Although L6 CT cells are not the only cortical pyramidal cells to innervate the thalamus, it is the taller, upper L6 CT cell axons that innervate the $\mathrm{nRT}$ as well as primary sensory regions, such as the LGN. Here they make rod-like terminal arbours, synapsing with the distal dendrites of relay cells and providing what has been termed 'modulatory input' (Sherman and Guillery, 1998). These upper layer 6 pyramidal cell axons do not send branches to other thalamic nuclei, or to other subcortical structures. In contrast, lower L6 CT cell axons innervate both primary sensory thalamus, with distal, rod-like terminations and secondary or association thalamic regions, while L5 pyramidal cells project only to intralaminar, or association areas of the thalamus (see Figure 4). These cortical pro- 
jections to secondary or association areas often form larger boutons and complex glomerular synapses with the proximal dendrites of relay cells (Usrey and Fitzpatrick, 1996; Murphy et al., 2000) (for properties of layer 5B CT synapses see Groh et al., 2008). Primary auditory cortico-thalamic connections exhibit similar differences between the projections from layers 5 and upper and lower layer 6 to those seen in the visual system (Ojima, 1994; Llano and Sherman, 2008). Unlike the axons of layer 6 cells, layer 5 cell axons that innervate the thalamus also innervate other subcortical structures, leading to the suggestion that secondary sensory and motor thalamus also receive a parallel readout of motor instructions from the cortex (Guillery, 2005; Sherman, 2005).

\section{TARGETS IN THALAMUS CORRELATE WITH CORTICAL PROJECTIONS}

Thus, primary sensory thalamus receives tightly coupled excitatory 'feed-back' from the appropriate primary sensory region of the cortex, via relatively slow, facilitating connections onto the distal dendrites of relay cells. These cells also receive disynaptic inhibition via cortico-thalamic activation of the $\mathrm{nRT}$. In primary sensory thalamic regions, the more powerful, fast, proximally located, depressing excitatory inputs come from the periphery (see Figure 4). Whether the terminations of somatosensory cortico-thalamic axons display a sub-modality selectivity equivalent to that displayed by the peripheral inputs remains to be determined (for discussion see Diamond et al., 1969; Murphy and Sillito, 1996; Deschênes et al., 1998). There is evidence for such selectivity in macaque visual cortex, with some segregation between the lower layer 6 projections to the magnocellular and upper layer 6 projections to parvocellular compartments of the LGN. Cells in the middle of the layer did not appear to project to the LGN (Fitzpatrick et al., 1994; and in tree shrew, Fitzpatrick, 1996). In a retrograde labelling study also in macacque V1, the neurones in upper layer 6 that projected to parvocellular LGN regions, also projected to lower $4 \mathrm{C}$, which receives $\mathrm{P}$ cell input. In contrast, cells in lower layer 6 that projected to magnocellular regions of LGN, projected to upper layer 4, which receives $\mathrm{M}$ cell input. Mid layer 4C the zone of $\mathrm{M}$ and $\mathrm{P}$ combination, received from the middle of layer 6 (which did not project to the $\mathrm{LGN}$ ), while $\mathrm{P}$ cell-recipient layer $4 \mathrm{~A}$ received projections from both upper and lower layer 6 (Yoshioka et al., 1994) (see Figure 3). These findings support an earlier proposal, that layer 6 pyramidal neurones target both specific sub-populations of LGN relay cells and the specific cells in layer 4 that are postsynaptic to those LGN cells (Lund and Boothe, 1975).

The major extra-areal input to layer 4 of the second visual area, $\mathrm{V} 2$, is provided by CC projections from $\mathrm{V} 1$, ie. these inputs occupy the territory that is occupied by thalamic afferents in V1. The output synapses from V2 CT cells to the pulvinar complex, a large region of association thalamus, occupy proximal dendritic locations and involve large glomerular synapses, similar to the types of synapses that relay information from the periphery to primary sensory thalamic nuclei. In contrast to this $\mathrm{V} 2$ projection, which comes largely from layer 6 , the projection from V1 to the pulvinar arises from layer $5 \mathrm{~B}$. Thus pulvinar receives highly processed information from more than one region of cortex, several synapses away from the LGN inputs to V1. In turn, the pulvinar provides the major subcortical input to V2 via lower layer 3, innervating both thick and thin stripes of high cytochrome oxidase activity (Levitt et al., 1995).

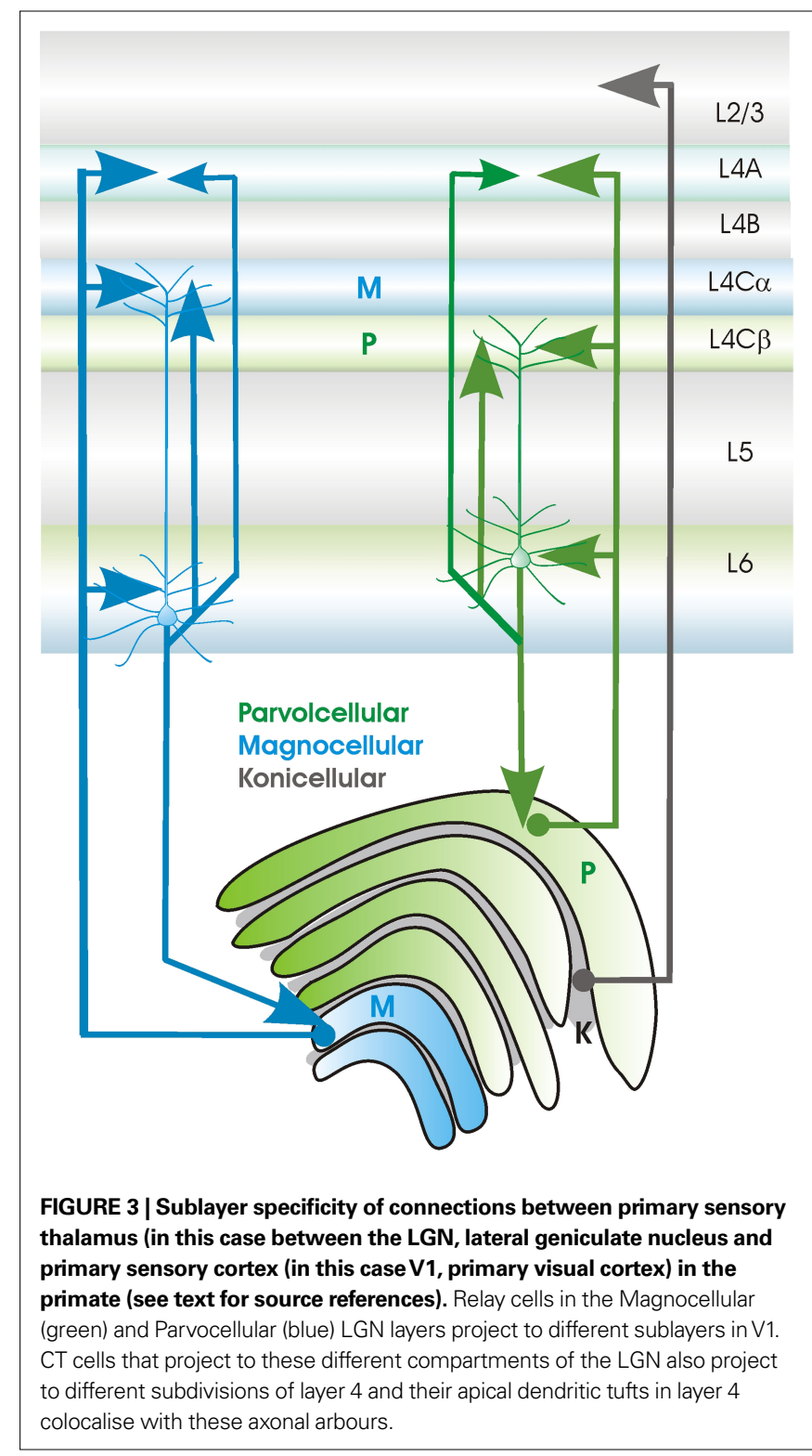

Similarly, in the somatosensory system, primary sensory cortical layer 5 projections to the secondary thalamic posterior group, Po, form clusters of large boutons, which are confined to the dorsal part of the nucleus. This part of Po, also receives input from layer 6 of the primary and second somatosensory areas and from the motor and insular cortices (Veinante et al., 2000). The relay cells in the head of the barreloids in primary sensory VPm also receive input from layer 6 of the vibrissa motor cortex. Unlike other regions of the barreloids, each of which is primarily responsive to a single whisker, these relay cells receive input from multi-whisker-responsive trigeminal neurones. Urbain and Deschênes (2007) propose that this pathway may relay information about the phase of whisker motion during free 'whisking'.

The interactions between cortex and thalamus are thus complex, but orderly. Primary sensory regions of thalamus that receive strong, proximal input from the periphery, project specifically and with a highly organised topography, to layers 4 and 6 (and in some 
cases to lower layer 3 ) of primary sensory cortex and receive modulatory input from layer 6 of precisely the same region. These inputs and outputs are further segregated in some modalities according to tightly matched layer 4 and thalamic nucleus subdivisions (see Figure 3). Secondary or association regions of thalamus receive their strong proximal inputs from another subclass of CT cells that do not project solely to primary sensory thalamus and from layer 5 cells in primary sensory cortex. Their cortico-thalamic modulatory inputs from secondary sensory cortex. These regions project to non-thalamo-recipient layers 1,2, upper 3 and 5 of primary sensory cortex, but to layer 4 of secondary sensory cortex (see Figure 4).

Corticothalamic synapses in primary sensory thalamic regions differ significantly from those provided by afferent sensory axons. They are smaller and more distally located on relay cell dendrites, utilise NR2B and $m$ GluR1 receptors in addition to the AMPA receptors that dominate afferent inputs and facilitate, rather than depress on repetitive activation. These inputs are described as modulatory. Primary sensory CT cells, typically found in upper layer 6, with axonal and dendritic arbours in layer 4, innervate primary sensory thalamic regions reciprocally and have axon collaterals that innervate $n R T$. In primate visual cortex, sublayer specificity is apparent in the regions of layer 4 and the layers in LGN that are supplied by these CT cell axons

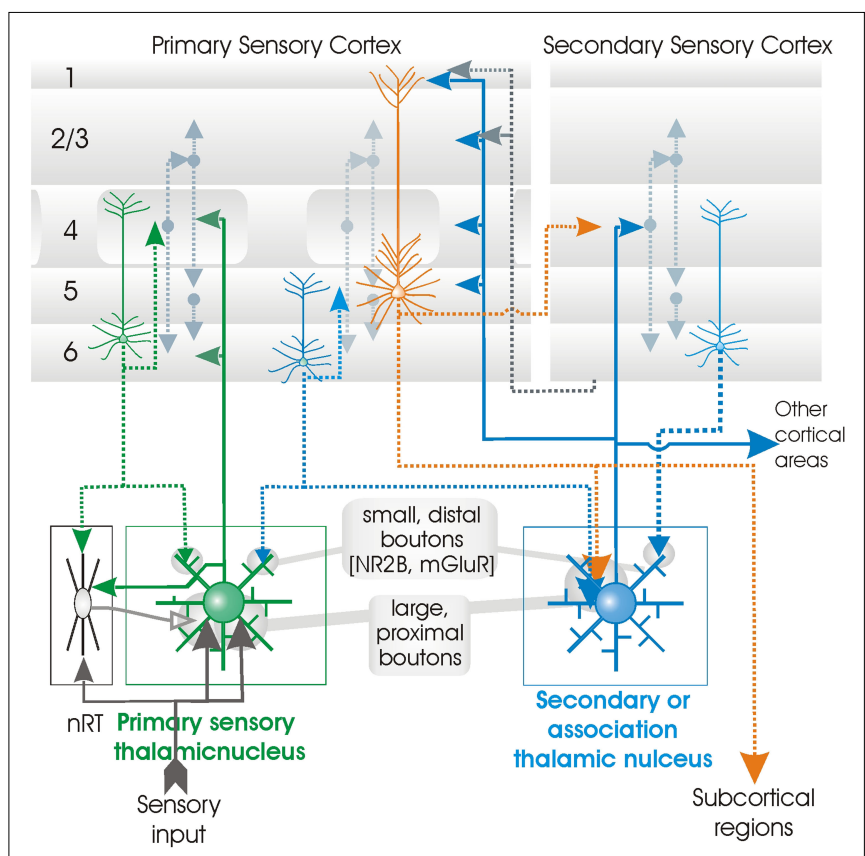

FIGURE 4 | Cartoon depicting some of the major connections between the neocortex and thalamus. The axons of cortical neurones are indicated by dotted lines, axons from thalamic cells by solid lines. The relationships summarised here appear broadly similar in somatosensory, visual and auditory systems. Layer 6 CT cells innervate the distal dendrites of relay cells in specific thalamic regions (eg. LGN, VPm, MGBv), with small boutons that seem to play a modulatory rle. In these nuclei, sensory input from the periphery provides the more powerful, faster input via large, proximal synapses. In association thalamic areas, the larger, more proximal synapses are provided by layer 6 CT cells and layer 5 corticofugal cells in primary cortex, while the smaller, more distal inputs come from association cortex. This is analogous to the powerful input to layer 4 in primary sensory cortex which comes from 'specific' thalamus, while layer 4 of the secondary cortical region receives information about the outside world from the appropriate primary sensory region of cortex. and, moreover, their distal dendritic tufts in layer 4 exhibit the same sublayer preferences. The other class of CT cells, typically found in deep layer 6 are shorter upright pyramids with axonal and dendritic arbours that terminate in layer 5 (some have axons that ramify in layer 2/3). They innervate primary sensory thalamus reciprocally, with modulatory synapses, but, like layer 5 pyramids, they also innervate secondary and association regions of thalamus with large more proximal boutons. They do not, however, innervate $n R T$.

\section{FUNCTION(S) OF CORTICOTHALAMIC CONNECTIONS}

This section focusses on the visual system where so called 'thalamo-cortical feed-back' has been most studied. LGN cells have lower background and stimulus-driven firing rates than their retinal inputs. Their responses increase more steeply with contrast, their centre-surround antagonism is greater and their spatial properties are more complex than those of their retinal inputs (Kaplan et al., 1987, see also discussion in Raiguel et al., 2006). These differences have, in part, been ascribed to the properties of the retinal input synapses and to local inhibitory circuitry (see also Wang et al., 2007), but cortico-thalamic input also plays an important role. Indeed, it is difficult to imagine a projection as powerful as the corticothalamic projection serving no significant function. The role of cortico-thalamic 'feedback' in co-ordinating oscillatory activity in the thalamocortical system is reviewed in Destexhe (2000).

\section{ORIENTATION AND DIRECTION PREFERENCES}

The elongate axonal arbours of some CT cells, which extend well beyond the dendritic trees of single relay cells, are proposed to innervate rows of LGN cells (whose receptive fields represent bars or lines in visual space), promoting their simultaneous activation. Coincident activity in rows of LGN relay cells aligned with the stimulus orientation would enhance orientation sensitivity, while activation of rows with different orientations might enhance sensitivity to direction (Murphy et al., 1999). In the LGN, the axonal arbours of CT cells are retinotopically organised, as are their effects on LGN cell receptive fields. Interestingly, these effects are reversed in phase relative to their ON and OFF zones (Wang et al., 2006).

\section{LENGTH TUNING}

Despite relatively concentric receptive fields, length-tuning is apparent in the LGN A laminae (Jones and Sillito, 1991), ie. increasing the length of the stimulus results in a decrease in the LGN response. The inhibitory perigeniculate nucleus (PGN, a subdivision of $\mathrm{nRT}$ ) clearly contributes to this tuning, since pairs of receptive fieldmatched LGN and PGN cells exhibit mirror image firing (Funke and Eysel, 1998). Some components of PGN- and thus LGN- length tuning may result from subcortically derived PGN receptive field structure, since PGN responses to long bars were not influenced by silencing the cortex (Jones and Sillito, 1994), The cortex does, nevertheless, refine the transfer of information from the thalamus in a manner that is dependent on the stimulus context (Cudeiro and Sillito, 1996). Layer 6 primary sensory CT cells are good candidates for cells that can activate centre-surround antagonism in the thalamus. They provide reciprocal innervation of primary sensory nuclei with parallel innervation of the nRT (including the PGN) and some layer 6 cells have extremely long receptive fields (approximately $17 \%$ of layer 6 cells in V1 had fields greater than 
$8^{\circ}$, Grieve and Sillito, 1991a). Of particular relevance to their influence on thalamic responses, layer 6 cell responses increase when stimuli (eg. drifting gratings) that cover the centre and surround components of their receptive fields respectively, are aligned and have the preferred orientation. LGN cells, on the other hand, are minimally responsive under these conditions (Sillito et al., 1993). Moreover, suppression of LGN cell receptive field centre responses by activation of the surround, and the impact, in the LGN, of centre-surround alignment, were lost when cortico-thalamic inputs to the LGN were silenced (Cudeiro and Sillito, 1996).

Inactivating layer 6 decreased end-inhibition in layer 4 and in cells in layers 2 and 3 that receive their major inputs from layer 4 . This effect was specific to end-inhibition as orientation and direction selectivity were unaffected (Bolz and Gilbert, 1986). However, the extent to which layer 6 cell activation of layer 4 interneurones contributes to end zone inhibition in layer 4 continues to be controversial. For example, in another series of experiments in cat visual cortex, pharmacological blockade of layer 6 decreased the response to the optimal length in layer 2-4 hypercomplex end-stopped cells, rather than increasing the response to longer stimuli. From this result, Grieve and Sillito (1991b) concluded that the predominant effect of layer 6 on layer 4 is mediated via excitatory input from layer 6 to 4 , rather than via the recruitment, by layer 6 cells, of inhibition in layer 4 .

\section{GAIN CONTROL}

A role for cortico-thalamic connections in LGN response gain control has also been proposed. In responses to moving, oriented stimuli (drifting gratings), cortico-thalamic input promotes correlated firing, in the LGN, of cells whose alignment within the receptive field matches that of the stimulus (Sillito et al., 1994). When correlated LGN cell firing was used to construct orientation-tuning curves, these were more sharply tuned when corticothalamic input was intact (Andolina et al., 2007). Since coincident presynaptic spikes and the resultant EPSPs are more likely to sum to firing threshold than widely separated EPSPs in thalamo-recipient cortical cells (Pinto et al., 2000; Bruno and Sakmann, 2006) and since supra-linear summation of these inputs has been reported (eg. Usrey et al., 2000; Roy and Alloway, 2001), the synchronisation of thalamic inputs to the cortex, by cortico-thalamic connections, may have important influences on cortical responsiveness to sensory input.

The mGluR1 component of synaptic activation in the thalamus that is specific to cortico-thalamic inputs, has been exploited to study CT cell influences on LGN receptive field structure. By manipulating these receptors pharmacologically in adult cat, cortico-thalamic, mGluR1- mediated input was found to enhance the excitatory centre of LGN receptive fields selectively. Moreover, the effect of manipulating mGluR1 activation was maximal with stimuli that drive cortical cells most effectively (Rivadulla et al., 2002).

\section{REFERENCES}

Alexander, G. M., Fisher, T.L., and Godwin, D. W. (2006). Differential response dynamics of corticothalamic glutamatergic synapses in the lateral geniculate nucleus and thalamic reticular nucleus. Neuroscience 137, 367-372.
Alexander, G. M., and Godwin, D. W. (2005). Presynaptic inhibition of corticothalamic feedback by metabotropic glutamate receptors. J. Neurophysiol. 94, 163-175.

Ali, A. B., Bannister, A. P., and Thomson, A. M. (2007). Robust correlations

The influences that layer 6 has on the responses of other cortical and thalamic neurones to sensory input, clearly remain controversial. That cortex influences thalamus is not in dispute. Orientation and direction tuning, length tuning and gain control in the thalamus all appear to be influenced by the cortex, ie. by layer 6 CT cells. It is the extent of this influence, in comparison with that of local thalamic mechanisms, and the precise conditions under which it is generated, that remain controversial. The relative paucity of compelling evidence results largely from the complexities of the system and the many cell classes and types of connections that shape these responses in thalamus and cortex. It is extremely difficult to manipulate and monitor a single type of neurone, or connection, in an entirely controlled way, to investigate its effect on such a system, without influencing the activity of others. The selective pharmacology approach has been used successfully in some such studies and could be exploited further. It is also possible that small rodents in which receptors have been modified in selected neuronal populations, or in which light-responsive ion channels are expressed in specific cell types, may provide useful tools.

\section{Does layer 6 provide 'feed-back'?}

Despite the powerful reciprocal connections between primary sensory thalamic nuclei and layer 6 of primary sensory cortical regions, the terms 'feed-forward' and 'feed-back' have been purposely avoided in this review. In an active brain these terms are nonsensical. They imply that one limb of a circuit sits there idly doing nothing and playing no part in circuit behaviour until, or unless, the other limb has activated it. Types of neurones and even complete circuits have, misguidedly, been defined in these terms, but where in the cortex, or thalamus, are there cell types that receive only one input, or that fire only in response to one type of signal, to be found? Layer 6 CT neurones may receive direct input from thalamic relay cells and send excitatory input to those same neurones (and/or their close neighbours), but they also receive strong inputs from within the cortex. These inputs, possibly from a neighbouring topographic region, could as easily cause a group of CT cells to modify the response of a thalamic relay cell to a novel incoming input, as a thalamo-cortical input could, via layer 6, modify the response of its cells of origin to a repetition of the same stimulus. It may be more useful to consider pathways such as those from cortex to thalamus and from regions of association cortex to primary sensory regions, as inputs that prime these lower order regions to transmit behaviourally relevant information within the current context; cognitive feed-forward perhaps, as much as sensory feed-back.

\section{ACKNOWLEDGMENTS}

My thanks to Antoine Brémaud and David West for helpful comments on the MS. The work from this laboratory summarised here was funded by the Medical Research Council, the EU Framework 6 (FACETS), the EPSRC (COLAMN) and Novartis Pharma Basel.

between action potential duration and the properties of synaptic connections in layer 4 interneurones in juvenile and adult neocortical slices. $J$. Physiol. (Lond.) 580, 149-169.

Anderson, J. C., Douglas, R. J., Martin, K. A., and Nelson, J.C. (1994). Map of the synapses formed with the dendrites of spiny stellate neurons of cat visual cortex. J. Comp. Neurol. 341, 25-38.

Andolina, I. M., Jones, H. E., Wang, W., and Sillito, A. M. (2007). Corticothalamic feedback enhances stimulus response precision in the 
visual system. Proc. Natl. Acad. Sci. U.S.A. 104, 1685-1690.

Arimatsu, Y., and Ishida, M. (2002). Distinct neuronal populations specified to form corticocortical and corticothalamic projections from layer VI of developing cerebral cortex. Neuroscience 114, 1033-1045.

Arimatsu, Y., Ishida, M., Sato, M., and Kojima, M. (1999a). Corticocortical associative neurons expressing latexin: specific cortical connectivity formed in vivo and in vitro. Cereb. Cortex 9S, 569-576.

Arimatsu, Y., Kojima, M., and Ishida, M. (1999b). Area- and lamina-specific organization of a neuronal subpopulation defined by expression of latexin in the rat cerebral cortex. Neuroscience 88, 93-105.

Auladell, C., Pérez-Sust, P., Supèr, H., and Soriano, E. (2000). The early development of thalamocortical and corticothalamic projections in the mouse. Brain Struct. Funct. 202, 169-179.

Bai, W. Z., Ishida, M., and Arimatsu, Y. (2004). Chemically defined feedback connections from infragranular layers of sensory association cortices in the rat. Neuroscience 123, 257-267.

Bannister, A. P., and Thomson, A. M. (2007). Dynamic properties of excitatory synaptic connections involving layer 4 pyramidal cells in adult rat and cat neocortex. Cereb. Cortex 17, 2190-2203.

Beierlein, M., and Connors, B. W. (2002). Short-term dynamics of thalamocortical and intracortical synapses onto layer 6 neurons in neocortex. $J$. Neurophysiol. 88, 1924-1932.

Binns, K. E., Turner, J. P., and Salt, T. E. (2003). Kainate receptor (GluR5)mediated disinhibition of responses in rat ventrobasal thalamus allows a novel sensory processing mechanism. J. Physiol. (Lond.) 551, 525-537.

Bolz, J., and Gilbert, C. D. (1986). Generation of end-inhibition in the visual cortex via interlaminar connections. Nature 320, 362-365.

Bolz, J., and Gilbert, C. D. (1989). The role of horizontal connections in generating long receptive fields in the cat visual cortex. Eur. J. Neurosci. 1, 263-268.

Bourassa, J., and Deschênes, M. (1995). Corticothalamic projections from the primary visual cortex in rats: a single fiber study using biocytin as an anterograde tracer. Neuroscience 66, 253-263.

Bourassa, J., Pinault, D., and Deschênes, M. (1995). Corticothalamic projections from the cortical barrel field to the somatosensory thalamus in rats: a single-fibre study using biocytin as an anterograde tracer. Eur. J. Neurosci. 7, 19-30.
Brémaud, A., West, D. C., and Thomson, A. M. (2007). Binomial parameters differ across neocortical layers and with different classes of connections in adult rat and cat neocortex. Proc. Natl. Acad. Sci. U.S.A. 104, 14134-14139.

Bruno, R. M., and Sakmann, B. (2006) Cortex is driven by weak but synchronously active thalamocortical synapses. Science 312, 1622-1627.

Callaway, E. (1998). Local circuits in primary visual cortex of the macaque monkey. Annu. Rev. Neurosci. 21, 47-74.

Callaway, E. M., and Lieber, J. L. (1996). Development of axonal arbors of layer 6 pyramidal neurons in ferret primary visual cortex. J. Comp. Neurol. 376, 295-305.

Castro-Alamancos, M. A. (2002). Properties of primary sensory (lemniscal) synapses in the ventrobasal thalamus and the relay of high-frequency sensory inputs. J. Neurophysiol. 87, 946-953.

Caviness, V. S., and Rakic, P. (1978) Mechanisms of cortical development a view from mutations in mice. Ann Rev. Neurosci. 1, 297-326.

Chen, C. C., Abrams, S., Pinhas, A., and Brumberg,J.C. (2009). Morphological heterogeneity of layer VI neurons in mouse barrel cortex. J. Comp. Neurol. 512, 726-746.

Clascá, F., Angelucci, A., and Sur, M. (1995). Layer-specific programs of development in neocortical projection neurons. Proc. Natl. Acad. Sci. U.S.A. 92, 11145-11149.

Cudeiro, J., and Sillito, A. M. (1996). Spatial frequency tuning of orientation-discontinuity- sensitive corticofugal feedback to the cat lateral geniculate nucleus. J. Physiol. (Lond) 490, 481-492.

Deschênes, M., Veinante, P., and Zhang, Z. W. (1998). The organization of corticothalamic projections: reciprocity versus parity. Brain Res. Rev $28,286-308$

Destexhe (2000). Modelling corticothalamic feedback and the gating of the thalamus by the cerebral cortex. $J$. Physiol. (Paris) 94, 391-410.

Deuchars, J., and Thomson, A. M. (1995). Innervation of burst firing interneurones by pyramidal cells in deep layers of rat somatomotor cortex: paired intracellular recordings with biocytin filling. Neuroscience 69, 739-755.

Diamond, I. T., Jones, E. G., and Powell, T. P. S. (1969). The projection of the auditory cortex upon the diencephalon and brainstem in the cat. Brain Res. 15 , 305-340.

Dufour, A., Seibt, J., Passante, L., Depaepe, V., Ciossek, T., Frisén, J., Kullander, K., Flanagan, J. G., Polleux, F., and Vanderhaeghen, P. (2003). Area spe- cificity and topography of thalamocortical projections are controlled by ephrin/Eph genes. Neuron 39 , 453-465.

Emri,Z., Antal, K., and Crunelli, V. (2003) The impact of corticothalamic feedback on the output dynamics of a thalamocortical neurone model: the role of synapse location and metabotropic glutamate receptors. Neuroscience 117, 229-239.

Fitzpatrick, D. (1996). Functional organization of local circuits in visual cortex: Insights from the study of tree shrew striate cortex. Cereb. Cortex 6 329-341.

Fitzpatrick, D., Usrey, W. M., Schofield, B. R., and Einstein, G. (1994). The sublaminar organization of corticogeniculate neurons in layer 6 of macaque striate cortex. Vis. Neurosci. $11,307-315$.

Friauf, E., McConnell, S. K., and Shatz, C. J. (1990). Functional synaptic circuits in the subplate during fetal and early postnatal development of cat visual cortex. J. Neurosci. 10 2601-2613.

Funke, K., and Eysel, U. T. (1998). Inverse correlation of firing patterns of single topographically matched perigeniculate neurons and cat dorsal latera geniculate relay cells. Vis. Neurosci. $15,711-729$.

Godwin, D. W., Van Horn, S. C., Eriir, A. Sesma, M., Romano, C., and Sherman, S. M. (1996). Ultrastructural localization suggests that retinal and cortical inputs access different metabotropic glutamate receptors in the latera geniculate nucleus. J. Neurosci. 16 8181-8192.

Golshani, P., Liu, X. B., and Jones, E. G. (2001). Differences in quanta amplitude reflect GluR4- subunit number at corticothalamic synapses on two populations of thalamic neurons. Proc. Natl. Acad. Sci. U.S.A. 98 4172-4177.

Gonchar, Y., Wang, Q., and Burkhalter, A. (2007). Multiple distinct subtypes of GABAergic neurons in mouse visual cortex identified by triple immunostaining. Front. Neuroanat. 1:3. doi:10.3389/neuro.05.003.2007.

Granseth, B.,Ahlstrand,E., and Lindstrom, S. (2002). Paired pulse facilitation of corticogeniculate EPSCs in the dorsa lateral geniculate nucleus of the rat investigated in vitro. J. Physiol. (Lond.) $544,477-486$

Grieve, K. L., and Sillito, A. M. (1991a). The length summation properties of layer VI cells in the visual cortex and hypercomplex cell end zone inhibition. Exp. Brain Res. 84, 319-325

Grieve, K. L., and Sillito, A. M. (1991b). A re-appraisal of the role of layer VI of the visual cortex in the generation of cortical end inhibition. Exp. Brain Res. 87, 521-529.

Groh, A., de Kock, C. P., Wimmer, V. C. Sakmann, B., and Kuner, T. (2008). Driver or coincidence detector: modal switch of a corticothalamic giant synapse controlled by spontaneous activity and short-term depression. J. Neurosci. 28, 9652-9663.

Guillery, R. W. (2005). Anatomical pathways that link perception and action. Prog. Brain Res. 149, 235-256.

Hevner, R. F., Shi, L., Justice, N., Hsueh, Y., Sheng, M., Smiga, S., Bulfone, A., Goffinet, A. M., Campagnoni, A. T., and Rubenstein, J.L. (2001). Tbrl regulates differentiation of the preplate and layer 6. Neuron 29, 353-366.

Hirsch, J.A., Gallagher, C.A., Alonso, J.M., and Martinez, L. M. (1998). Ascending projections of simple and complex cells in layer 6 of the cat striate cortex. J. Neurosci. 18, 8086-8094.

Huang, Z. (2009). Molecular regulation of neuronal migration during neocortical development. Mol. Cell. Neurosci. $42,11-22$.

Hughes, S. W., Lorincz, M., Cope, D. W., Blethyn, K. L., Kekesi, K. A., Parri, H. R., Juhasz, G., and Crunelli, V. (2004). Synchronized oscillations at alpha and theta frequencies in the lateral geniculate nucleus. Neuron 42, 253-268.

Ince-Dunn, G., Hall, B. J., Hu, S. C. Ripley, B., Huganir, R. L., Olson, J. M. Tapscott, S. J., and Ghosh, A. (2006) Regulation of thalamocortical patterning and synaptic maturation by NeuroD2. Neuron 49, 683-695.

Issa, N.P., Trachtenberg, J. T., Chapman, B., Zahs, K. R., and Stryker, M. P. (1999). The critical period for ocular dominance plasticity in the ferret's visual ortex. J. Neurosci. 19, 6965-6978.

Jones, E. G. (1998). Viewpoint: the core and matrix of thalamic organization. Neuroscience 85, 331-345.

Jones, E. G., and Powell, T. P. (1969). The cortical projection of the ventroposterior nucleus of the thalamus in the cat. Brain Res. 13, 298-318.

Jones, H. E., and Sillito, A. M. (1991). The length-response properties of cells in the feline dorsal lateral geniculate nucleus. J. Physiol. (Lond.) 444, 329-348.

Jones, H. E., and Sillito, A. M. (1994). The length-response properties of cells in the feline perigeniculate nucleus. Eur. J. Neurosci. 6 1199-1204.

Kaplan, E., Purpura, K., and Shapley, R. M. (1987). Contrast affects the transmission of visual information through the mammalian lateral geniculate nucleus. J. Physiol. (Lond.) 391, 267-288.

Katz, L. C. (1987). Local circuitry of identified projection neurons in cat 
visual cortex brain slices. J. Neurosci. 7, 1223-1249.

Kawaguchi, Y., and Kubota, Y. (1996). Physiological and morphological identification of somatostatin- or vasoactive intestinal polypeptide-containing cells among GABAergic cell subtypes in rat frontal cortex. J. Neurosci. 16, 2701-2715.

Kostovic, I., and Rakic, P. (1990). Developmental history of the transient subplate zone in the visual and somatosensory cortex of the macaque monkey and human brain. J. Comp. Neurol. 297, 441-470.

Kwan, K. Y., Lam, M. M., Krsnik, Z., Kawasawa, Y. I., Lefebvre, V., and Sestan, N. (2008). SOX5 postmitotically regulates migration, postmigratory differentiation, and projections of subplate and deep-layer neocortical neurons. Proc. Natl. Acad. Sci. U.S.A. 105, 16021-16026.

Landisman, C. E., and Connors, B. W. (2007). VPM and PoM nuclei of the rat somatosensory thalamus: intrinsic neuronal properties and corticothalamic feedback. Cereb. Cortex 17, 2853-2865.

Lee, C. C., and Sherman, S. (2009). Modulator property of the intrinsic cortical projection from layer 6 to layer 4. Front. Syst. Neurosci. 3:3. doi:10.3389/neuro.06.003.2009.

Levitt, J. B., Yoshioka, T., and Lund, J. S. (1995). Connections between the pulvinar complex and cytochrome oxidase-defined compartments in visual area $\mathrm{V} 2$ of macaque monkey. Exp. Brain Res. 104, 419-430.

Little, G. E., López-Bendito, G., Rünker, A. E., García, N., Piñon, M. C. Chédotal,A., Molnár,Z., and Mitchell, K. J. (2009). Specificity and plasticity of thalamocortical connections in Sema6A mutant mice. PLoS Biol. 7, e98. doi:10.1371/journal. pbio.1000098.

Llano, D. A., and Sherman, S. M. (2008). Evidence for nonreciprocal organization of the mouse auditory thalamocortical-corticothalamic projection systems. J. Comp. Neurol. 507, 1209-1227.

Lund, J. (1988). Anatomical organization of macaque monkey striate visual cortex. Annu. Rev. Neurosci. 11, 253-288.

Lund, J. S., and Boothe, R. (1975). Interlaminar connections and pyramidal neuron organization in the visual cortex, area 17, of the macaque monkey. J. Comp. Neurol. 159, 305-334.

Lund,J. S., Griffiths, S., Rumberger, A., and Levitt, J. B. (2001). Inhibitory synapse cover on the somata of excitatory neurons in macaque monkey visual cortex. Cereb. Cortex 11, 783-795.
Lund, J. S., Hawken, M. J., and Parker, A. J. (1988). Local circuit neurons of macaque monkey striate cortex: II. Neurons of laminae 5B and 6.J. Comp. Neurol. 276, 1-29.

Lund, J. S., and Yoshioka, T. (1991). Local circuit neurons of macaque monkey striate cortex: III. Neurons of laminae 4B, 4A, and 3B. J. Comp. Neurol. 311 , 234-258.

Markram, H., Wang, Y., and Tsodyks, M. (1998). Differential signaling via the same axon of neocortical pyramidal neurons. Proc. Natl. Acad. Sci. U.S.A. $95,5323-5328$

Martinez, L. M., Wang, Q., Reid, R. C., Pillai, C., Alonso, J. M., Friedrich, T. S., and Hirsch, J. A. (2005). Receptive field structure varies with layer in the primary visual cortex. Nat. Neurosci. 8, 372-379.

Mason, C. A., Guillery, R. W., and Rosner, M. C. (1984). Patterns of synaptic contact upon individually labeled large cells of the dorsal lateral geniculate nucleus of the cat. Neuroscience 11 319-334.

McConnell, S. K., Ghosh, A., and Shatz, C. J. (1989). Subplate neurons pioneer the first axon pathway from the cerebral cortex. Science 245, 978-982.

McGuire, B. A., Hornung, J. P., Gilbert, C. D., and Wiesel, T.N. (1984). Patterns of synaptic input to layer 4 of cat striate cortex. J. Neurosci. 4, 3021-3033.

Mercer, A., West, D. C., Morris, O. T. Kirchhecker, S., Kerkhoff, J. E., and Thomson, A. M. (2005). Excitatory connections made by presynaptic cortico-cortical pyramidal cells in layer 6 of the neocortex. Cereb. Cortex 15 1485-1496.

Miyata, M., and Imoto, K. (2006). Different composition of glutamate receptors in corticothalamic and lemniscal synaptic responses and their roles in the firing responses of ventrobasal thalamic neurons in juvenile mice. J. Physiol. (Lond.) 575, 161-174.

Murphy, P. C., Duckett, S. G., and Sillito, A. M. (1999). Feedback connections to the lateral geniculate nucleus and cortical response properties. Science 286, 1552-1554.

Murphy, P. C., Duckett, S. G., and Sillito, A.M. (2000). Comparison of the laminar distribution of input from areas 17 and 18 of the visual cortex to the lateral geniculate nucleus. J. Neurosci. 20, 845-853.

Murphy, P. C., and Sillito, A. M. (1996) Functional morphology of the feedback pathway from area 17 of the cat visual cortex to the lateral geniculate nucleus. J. Neurosci. 16 1180-1192.

Nassi, J. J., and Callaway, E. M. (2009). Parallel processing strategies of the primate visual system. Nat. Rev Neurosci. 10, 360-372.

Ojima, H. (1994). Terminal morphology and distribution of corticothalamic fibers originating from layers 5 and 6 of cat primary auditory cortex. Cereb. Cortex 4, 646-663.

Pinto, D. J., Brumberg, J. C., and Simons, D. J. (2000). Circuit dynamics and coding strategies in rodent somatosensory cortex. J. Neurophysiol. 83 , 1158-1166.

Porter, J. T., Cauli, B., Staiger, J. F., Lambolez, B., Rossier, J., and Audinat, E. (1998). Properties of bipolar VIPergic interneurons and their excitation by pyramidal neurons in the rat neocortex. Eur. J. Neurosci. 10, 3617-3628.

Raiguel, S., Vogels, R., Mysore, S. G., and Orban, G. A. (2006). Learning to see the difference specifically alters the most informative V4 neurons. J. Neurosci. 26, 6589-6602.

Rakic, P. (2009). Evolution of the neocortex: a perspective from developmental biology. Nat. Rev. Neurosci. 10, 724-735.

Reichova, I., and Sherman, S. M. (2004). Somatosensory corticothalamic projections: distinguishing drivers from modulators. J. Neurophysiol. 92 2185-2197.

Rivadulla, C., Martinez, L. M., Varela, C. and Cudeiro, J. (2002). Completing the corticofugal loop: a visual role for the corticogeniculate type 1 metabotropic glutamate receptor. J. Neurosci. 22, 2956-2962.

Roy, S. A., and Alloway, K. D. (2001) Coincidence detection or temporal integration? What the neurons in somatosensory cortex are doing. $J$. Neurosci. 21, 2462-2473.

Schubert, D., Kötter, R., Zilles, K. Luhmann, H. J., and Staiger, J. F (2003). Cell type-specific circuits of cortical layer IV spiny neurons. $J$. Neurosci. 23, 2961-2970.

Schwarz, C., and Bolz,J. (1991). Functional specificity of a long-range horizontal connection in cat visual cortex: a cross-correlation study. J. Neurosci. 11 2995-3007.

Sherman, S. M. (2005). Thalamic relays and cortical functioning. Prog. Brain Res. 149, 107-126.

Sherman, S. M., and Guillery, R. W. (1996). Functional organization of thalamocortical relays.J. Neurophysiol. 76, 1367-1395.

Sherman, S. M., and Guillery, R.W. (1998) On the actions that one nerve cell can have on another: distinguishing drivers from modulators. Proc. Natl. Acad. Sci. U.S.A. 95, 7121-7126.

Shimizu, T., and Hibi, M. (2009). Formation and patterning of the forebrain and olfactory system by zinc-finger genes Fezf1 and Fezf2. Dev. Growth Differ. 51, 221-231.

Sillito,A.M., Cudeiro, J., and Murphy, P.C. (1993). Orientation sensitive elements in the corticofugal influence on centre-surround interactions in the dorsal lateral geniculate nucleus. Exp. Brain Res. 93, 6-16.

Sillito, A. M., Jones, H. E., Gerstein, G. L., and West, D. C. (1994). Featurelinked synchronization of thalamic relay cell firing induced by feedback from the visual cortex. Nature 369, $479-482$.

Staiger, J. F., Zilles, K., and Freund, T. F. (1996a). Recurrent axon collaterals of corticothalamic projection neurons in rat primary somatosensory cortex contribute to excitatory and inhibitory feedback-loops. Anat. Embryol. 194, 533-543.

Somogyi, P., and Cowey, A. (1981). Combined Golgi and electron microscopic study on the synapses formed by double bouquet cells in the visual cortex of the cat and monkey. J. Comp. Neurol.195, 547-566.

Staiger, J. F., Zilles, K., and Freund, T. F. (1996b). Distribution of GABAergic elements postsynaptic to ventroposteromedial thalamic projections in layer IV of rat barrel cortex. Eur. J. Neurosci. 8, 2273-2285.

Tarczy-Hornoch, K., Martin, K. A., Stratford, K. J., and Jack, J. J. (1999). Intracortical excitation of spiny neurons in layer 4 of cat striate cortex in vitro. Cereb. Cortex 9, 833-843.

Thomson, A. M. (1997). Activitydependent properties of synaptic transmission at two classes of connections made by rat neocortical pyramidal axons in vitro. J. Physiol. (Lond.) 502, 131-147.

Thomson, A. M., and Bannister, A. P. (1998). Postsynaptic pyramidal target selection by descending layer III pyramidal axons: dual intracellular recordings and biocytin filling in slices of rat neocortex. Neuroscience 84, 669-683.

Thomson, A. M., and Bannister, A. P. (1999). Release independent depression at pyramidal inputs onto specific cell targets: dual intracellular recordings in slices of rat cortex. J. Physiol. (Lond.) 519, 57-70.

Thomson, A. M., Deuchars, J., and West, D. C. (1993). Large, deep layer pyramidpyramid, single axon EPSPs in slices of rat motor cortex display paired pulse and frequency dependent depression mediated presynaptically and self facilitation mediated postsynaptically. J. Neurophysiol. 70, 2354-2369.

Thomson, A. M., and Lamy, C. (2007). Functional maps of neocortical local circuitry. Front. Neurosci. 1, 19-42. doi:10.3389/neuro.01.1.1.002.2007. 
Thomson, A. M., West, D. C., and Deuchars, J. (1995). Properties of single axon EPSPs elicited in spiny interneurones by action potentials in pyramidal neurones in slices of rat neocortex. Neuroscience 69, 727-738.

Thomson, A. M., West, D. C., Wang, Y., and Bannister, A. P. (2002). Synaptic connections and small circuits involving excitatory and inhibitory neurones in layers 2 to 5 of adult rat and cat neocortex: triple intracellular recordings and biocytin-labelling in vitro. Cereb. Cortex 12, 936-953.

Turner, J. P., and Salt, T. E. (1998). Characterization of sensory and corticothalamic excitatory inputs to rat thalamocortical neurones in vitro. J. Physiol. 510, 829-843.

Urbain, N., and Deschênes, M. (2007). A new thalamic pathway of vibrissal information modulated by the motor cortex. J. Neurosci. 27, 12407-12412.

Usrey, W. M., Alonso, J. M., and Reid, R. C. (2000). Synaptic interactions between thalamic inputs to simple cells in cat visual cortex. J. Neurosci. 20, 5461-5467.
Usrey, W. M., and Fitzpatrick, D. (1996). Specificity in the axonal connections of layer VI neurons in Tree Shrew striate cortex: evidence for distinct granular and supragranular systems. J. Neurosci. 16, 1203-1218.

Veinante, P., Lavallée, P., and Deschênes, M. (2000). Corticothalamic projections from layer 5 of the vibrissal barrel cortex in the rat. J. Comp. Neurol. 424, 197-204.

Wang, W., Jones, H. E., Andolina, I. M., Salt, T. E., and Sillito, A. M. (2006). Functional alignment of feedback effects from visual cortex to thalamus. Nat. Neurosci. 9, 1330-1336.

Wang, X., Wei, Y., Vaingankar, V., Wang, Q., Koepsell, K., Sommer, F. T., and Hirsch, J.A. (2007).Feedforward excitation and inhibition evoke dual modes of firing in the cat's visual thalamus during naturalistic viewing. Neuron 55, 465-478.

West, D. C., Mercer, A., Kirchhecker, S., Morris, O. T., and Thomson, A. M. (2006). Layer 6 cortico- thalamic pyramidal cells preferentially innervate interneurons and generate facilitating EPSPs. Cereb. Cortex 16, 200-211.
Wiser, A. K., and Callaway, E. M. (1997). Ocular dominance columns and local projections of layer 6 pyramidal neurons in macaque primary visual cortex. Vis. Neurosci. 14, 241-251.

Wright, A. G., Demyanenko, G. P., Powell, A., Schachner, M., Enriquez-Barreto L., Tran, T. S., Polleux, F., and Maness, P. F. (2007). Close homolog of L1 and neuropilin 1 mediate guidance of thalamocortical axons at the ventral telencephalon. J. Neurosci. 27, 13667-13679.

Yoshioka, T., Levitt, J. B., and Lund, J. S. (1994). Independence and merger of thalamocortical channels within macaque monkey primary visual cortex: anatomy of interlaminar projections. Vis. Neurosci. 11, 467-489.

Zarrinpar, A., and Callaway, E. M. (2006) Local connections to specific types of layer 6 neurons in the rat visual cortex. J. Neurophysiol. 95, 1751-1761.

Zhang, Z. W., and Deschênes, M. (1997). Intracortical axonal projections of lamina VI cells of the primary somatosensory cortex in the rat: a singlecell labeling study. J. Neurosci. 17, 6365-6379.
Zhang,Z.W., and Deschênes, M. (1998). Projections to layer VI of the posteromedial barrel field in the rat: a reappraisal of the role of corticothalamic pathways. Cereb. Cortex 8 , 428-436.

Conflict of Interest Statement: The research from this group that is included here, was conducted in the absence of any commercial or financial relationships that could be construed as a potential conflict of interest.

Received: 12 January 2010; paper pending published: 27 January 2010; accepted: 03 March 2010; published online: 31 March 2010.

Citation: Thomson AM (2010) Neocortical layer 6, a review. Front. Neuroanat. 4:13. doi: 10.3389/fnana.2010.00013 Copyright (c) 2010 Thomson. This is an open-access article subject to an exclusive license agreement between the authors and the Frontiers Research Foundation, which permits unrestricted use, distribution, and reproduction in any medium, provided the original authors and source are credited. 